\title{
Systems of variational relations with lower semicontinuous set-valued mappings
}

\author{
Mircea BALAJ
}

\section{ABSTRACT.}

In this paper, we use fixed point techniques to establish existence criteria of the solution for a system of two variational relations with lower semicontinuous set-valued mappings.

\section{REFERENCES}

[1] Aliprantis, C. D. and Border, K. C., Infinite dimensional analysis. A hitchhiker's guide, Springer, Berlin, 2006

[2] Anh, L. Q. and Khanh, P. Q., Existence conditions in symmetric multivalued vector quasiequilibrium problems, Control Cybernet., 36 (2007), 519-530

[3] Ansari, Q. H., Lin, L. J. and Su, L. B., Systems of simultaneous generalized vector quasiequilibrium problems and their applications, J. Optim. Theory Appl., 127 (2005), 27-44

[4] Balaj, M. and Lin, L. J., Generalized variational relation problems with applications, J. Optim. Theory Appl., 148 (2011), 1-13

[5] Balaj, M. and Lin, L. J., Quasi-variational relation problems and generalized Ekeland's variational principle with applications, Optimization, 63 (2014), 1353-1365

[6] Balaj, M., Three types of variational relation problems, Taiwanese J. Math., 17 (2013), 47-61

[7] Cubiotti, P., Some remarks on fixed points of lower semicontinuous multifunctions, J. Math. Anal. Appl., 174 (1993), 407-412

[8] Fakhar, M. and Zafarani, J., Generalized symmetric vector quasiequilibrium problems, J. Optim. Theory Appl., 136 (2008), 397-409

[9] Fu, J. Y., Symmetric vector quasi-equilibrium problems, J. Math. Anal. Appl., 285 (2003), 708-713

[10] Hung, N. V., Sensitivity analysis for generalized quasi-variational relation problems in locally $G$ convex spaces, Fixed Point Theory Appl., 2012, 2012:158

[11] Hung, N. V., Existence conditions for symmetric generalized quasi-variational inclusion problems, J. Inequal. Appl., 2013, 2013:40

[12] Hung, N. V. and Kieu, P. T., On the existence and essential components of solution sets for systems of generalized quasi-variational relation problems, J. Inequal. Appl., 2014, 250 (2014)

[13] Lechicki, A. and Spakowski, A., A note on intersection of lower semicontinuous multifunctions, Proc. Amer. Math. Soc., bf 95 (1985), 119-122

[14] Lin, L. J. and Wang, S. Y., Simultaneous variational relation problems and related applications, Comput. Math. Appl., 58 (2009), 1711-1721

[15] Lin, L. J., Existence theorems of simultaneous equilibrium problems and generalized vector quasi-saddle points, J. Global Optim., 32 (2005), 613-632

[16] Luc, D. T., An abstract problem in variational analysis, J. Optim. Theory Appl., 138 (2008), 65-76

[17] Luc, D. T., Sarabi, E. and Soubeyran, A., Existence of solutions in variational relation problems without convexity, J. Math. Anal. Appl., 364 (2010), 544-555

Received: 14.09.2014; In revised form: 09.01.2015; Accepted: 31.01.2015

2010 Mathematics Subject Classification. 49J40, 49J53.

Key words and phrases. System of variational relations, set-valued mapping, fixed point. 
[18] Noor, M. A. and Oettli, W., On general nonlinear complementarity problems and quasi-equilibria, Matematiche, 49 (1994), 313-331

[19] Papageorgiou, N. S., On the existence of $\psi$-minimal viable solutions for a class of differential inclusions, Arch. Math. (Brno) 27B, (1991), 175-182

[20] Ricceri, O. N., On the covering dimension of the fixed point set of certain multifunctions, Commentat. Math. Univ. Carol., 32 (1991), 281-286

[21] Wu, X., A new fixed point theorem and its applications, Proc. Amer. Math. Soc., 125 (1997), 1779-1783

[22] Yang, Z. and Pu, Y. J., Existence and stability of solutions for maximal element theorem on Hadamard manifolds with applications, Nonlinear Anal., 75 (2012), 516-525

[23] Yang, Z. and Pu, Y. J., Generalized Knaster-Kuratowski-Mazurkiewicz theorem without convex hull, J. Optim. Theory Appl., 154 (2012), 17-29

[24] Yang, Z., Existence of solutions for a system of quasi-variational relation problems and some applications, Carpathian J. Math., 31 (2015), 135-142

[25] Yang, Z., On existence and essential stability of solutions of symmetric variational relation problems, J. Inequal. Appl., 2014, 2014:5

UNIVERSITY OF ORADEA

DEPARTMENT OF MATHEMATICS

UNIVERSITY STREET 1, 410087 ORADEA, ROMANIA

E-mail address: mbalaj@uoradea.ro 